\title{
Real-time W phase inversion during the 2011 off the Pacific coast of Tohoku Earthquake
}

\author{
Zacharie Duputel $^{1}$, Luis Rivera ${ }^{1}$, Hiroo Kanamori ${ }^{2}$, Gavin P. Hayes ${ }^{3,4}$, Barry Hirshorn ${ }^{5}$, and Stuart Weinstein ${ }^{5}$ \\ ${ }^{1}$ IPGS-EOST, CNRS/Universitéde Strasbourg, UMR 7516, Strasbourg, France \\ ${ }^{2}$ Seismological Laboratory, Caltech, Pasadena, USA \\ ${ }^{3}$ U.S. Geological Survey, National Earthquake Information Center, USA \\ ${ }^{4}$ Synergetics Inc., Fort Collins, Colorado, USA \\ ${ }^{5}$ NOAA, NWS, Pacific Tsunami Warning Center, Hawaii, USA
}

(Received April 8, 2011; Revised May 19, 2011; Accepted May 24, 2011; Online published September 27, 2011)

\begin{abstract}
The real time $\mathrm{W}$ phase source inversion algorithm was independently running at three organizations (USGS, PTWC and IPGS) at the time of the 2011 off the Pacific coast of Tohoku Earthquake. Valuable results for tsunami warning purposes were obtained $20 \mathrm{~min}$ after the event origin time. Within the next hour, as more data became available, the $\mathrm{W}$ phase solutions improved, and converged to a common result $\left(M_{\mathrm{w}} \approx 9.0\right.$, dip $\left.\approx 14^{\circ}\right)$. $\mathrm{A}$ post-mortem $\mathrm{W}$ phase analysis using data selection based on pre-event noise confirmed the $M_{\mathrm{w}}=9.0$ result and yielded a best double couple given by ( strike/dip/rake $=196^{\circ} / 12^{\circ} / 85^{\circ}$ ). We also ran the algorithm with increasingly longer periods $(T \approx 1500 \mathrm{sec})$ to test for the possibility of additional slow slip. The seismic moment remained stable, confirming the prior results.
\end{abstract}

Key words: Tsunamis, surface waves and free oscillations, wave propagation, Early Warning.

\section{Introduction}

Many moment tensor inversion codes are currently used at organizations providing real-time solutions of earthquakes. However, it is usually difficult to handle very large earthquakes $\left(M_{\mathrm{w}} \geq 8.0\right)$ with conventional real-time source inversion techniques. Until recently, it was often necessary to wait for at least several hours to obtain a reliable point source solution. One of the difficulties encountered is the clipping of seismograms by signals from great earthquakes. The large spatial and temporal scales of great events call for the use of very long period data, but these records are often clipped for such large events even at teleseismic distances at the arrival of the first surface wave trains.

The $\mathrm{W}$ phase source inversion algorithm was specifically developed to handle very large earthquakes like the recent 2011 off the Pacific coast of Tohoku Earthquake (hereafter, abbreviated to 2011 Tohoku Earthquake) and the 2010 Maule, Chile, earthquake. This method exploits the long period content of the broadband seismic record (200 sec$1000 \mathrm{sec}$ ) preceding the arrival of the surface waves. The interest in this new algorithm has rapidly grown because of its ability to quickly provide reliable source parameters of large earthquakes, which can subsequently be used as input for other applications such as ShakeMap generation (e.g. USGS, 2011a), tsunami propagation modeling, finite source inversions (e.g. USGS, 2011b), etc.

Copyright (C) The Society of Geomagnetism and Earth, Planetary and Space Sciences (SGEPSS); The Seismological Society of Japan; The Volcanological Society of Japan; The Geodetic Society of Japan; The Japanese Society for Planetary Sciences; TERRAPUB.

doi:10.5047/eps.2011.05.032

\section{Real-Time Results}

At the time of the 2011 Tohoku event, the $\mathrm{W}$ phase source inversion algorithm was running at three organizations with independent initial location estimates: (1) the National Earthquake Information Center (NEIC) of the United States Geological Survey (USGS), (2) the Pacific Tsunami Warning Center (PTWC) of the National Oceanic and Atmospheric Administration (NOAA) and (3) the Institut de Physique du Globe de Strasbourg (IPGS). The solutions obtained from each of these real-time operations are listed in Table 1 . As is generally the case with very large earthquakes, the initial magnitudes computed using traditional methods were lower than the actual earthquake's magnitude. The PTWC's first tsunami bulletin gave $M=7.9$ (PTWC, 2011), the USGS announced an $M=7.9$ (Hayes et al., 2011) and the European-Mediterranean Seismological Center's rapid determination of source parameters yielded $M=8.0$ (EMSC, 2011). This contrasts with the first W phase results at USGS and PTWC providing $M_{\mathrm{w}}$ estimations ranging from 8.8 to 9.0 within $30 \mathrm{~min}$ after O.T. Although these estimates show some differences, the uncertainty is small enough for warning purposes. The first solution obtained by the USGS was very good even though it was based on only 6 channels of seismic data. The first two PTWC solutions underestimated the earthquake's magnitude due to the large initial depth $(83.5 \mathrm{~km})$. At about 40 min after O.T. more data became available and the $\mathrm{W}$ phase solutions from the three institutions converged to $M_{\mathrm{w}} \approx 9.0$ with a fault dip of around $14^{\circ}$. 
Table 1. Real-Time W phase solutions obtained for the 2011 Tohoku Earthquake. The real-time instances of the W phase algorithm are running with a fixed depth, specified for each solution in the table.

\begin{tabular}{|c|c|c|c|c|c|c|}
\hline Delay & Origin & $M_{\mathrm{W}}$ & Strike/Dip/Rake, deg & Depth, km & \# chan. & Mech \\
\hline $20 \mathrm{~min}$ & USGS automatic trigger (internal) & 9.0 & $222.7 / 16.8 / 134.6$ & 24.4 & 6 & \\
\hline $22 \mathrm{~min}$ & PTWC automatic trigger 1 & 8.8 & $165.4 / 10.3 / 55.3$ & 83.5 & 29 & \\
\hline $30 \mathrm{~min}$ & PTWC automatic trigger 2 & 8.8 & $194.3 / 22.8 / 81.3$ & 83.5 & 74 & \\
\hline $40 \mathrm{~min}$ & PTWC manual trigger & 9.0 & $190.6 / 11.1 / 76.7$ & 24.4 & 105 & \\
\hline $45 \mathrm{~min}$ & IPGS automatic trigger 1 & 9.0 & $199.6 / 10.8 / 93.5$ & 24.4 & 31 & \\
\hline $48 \mathrm{~min}$ & USGS automatic trigger (internal) & 8.9 & 204.4/14.8/104.3 & 24.4 & 74 & \\
\hline $1 \mathrm{~h} 02 \mathrm{~min}$ & USGS Published & 8.9 & $162.0 / 16.9 / 45.1$ & 24.4 & 89 & \\
\hline $1 \mathrm{~h} 30 \mathrm{~min}$ & IPGS automatic trigger 2 & 9.0 & 196.3/14.4/85.1 & 24.4 & 146 & \\
\hline
\end{tabular}

\section{Post-mortem Results}

In this section we attempt to improve the real-time $\mathrm{W}$ phase solutions by using a subset of higher quality channels of seismic data. We retrieved the LH channels belonging to the FDSN, GSN and STS1 global virtual networks of IRIS within epicentral distances of $90^{\circ}$. Most of these channels used belong to the BK, CI, CN, G, GE, IC, II, $\mathrm{IU}, \mathrm{MN}$, and US networks, and four sensors are commonly used: STS-1, STS-2, KS-5400 and CMG-3T. We use time domain deconvolution to retrieve ground displacement and then filter between 1 and $5 \mathrm{mHz}$.

\subsection{First-order magnitude estimation}

Before trying a formal moment tensor inversion, we perform a first-order fit to the $\mathrm{W}$ phase amplitudes as a function of distance and azimuth. The idea here is to capture the information carried by the overall vertical $\mathrm{W}$ phase amplitudes, and translate these into a first-order moment magnitude estimate. After reduction to a common distance (e.g. $\Delta=40^{\circ}$ ), the peak-to-peak $\mathrm{W}$ phase amplitudes $p_{j}$ are matched to a simple two-lobed azimuthal pattern which accounts for the amplitude variation due to the mechanism (Kanamori and Rivera, 2008a; Duputel et al., 2011):

$$
p_{j}=q\left(\Delta_{j}\right)\left[a-b \cos ^{2}\left(\Phi_{j}-\Phi_{0}\right)\right]
$$

Where $\Delta_{j}, \Phi_{j}$ and $q\left(\Delta_{j}\right)$ respectively stand for the distance, azimuth and amplitude decay at station $j$, and $a, b$ and $\Phi_{0}$ are the parameters to be estimated. Figure 1 shows the amplitude-azimuth fit once the distance correction has been applied. The continuous line shows the result of the regression while the colored bars indicate the reduced peakto-peak measurements. The average $\mathrm{W}$ phase amplitude at $\Delta=40^{\circ}$ is estimated here to be $5 \mathrm{~mm}$ and the corresponding preliminary magnitude is $M_{\mathrm{w}}=9.1$. We also note that the orientation of the lobes is clearly indicative of the fault strike.

\subsection{Centroid moment tensor solution}

As discussed in Section 2, the initial real-time $\mathrm{W}$ phase solutions at all three institutions provided quite similar solutions, with $M_{\mathrm{w}}$ estimates ranging from 8.8 to 9.0 , and fault dip values distributed between $10^{\circ}$ and $20^{\circ}$, depending on the assumed initial depth. We explore here the possibility of narrowing this uncertainty by improving the overall signal-to-noise ratio through the careful selection of low noise stations, so as to best resolve the moment tensor elements. Since manual data selection is always questionable because it involves some subjective assessment of the waveform quality, a fully automated screening is used here. The screening scheme and criteria are detailed as follows.

The very first screening is a median screening, which consists of rejecting any seismograms with $\mathrm{W}$ phase peakto-peak value $p_{p}$ too different from the median peak-topeak $m_{p}$ of the whole dataset (i.e. $p_{p}<0.1 \times m_{p}$ or $\left.p_{p}>3 \times m_{p}\right)$. This rough screening has the advantage of being completely independent of the data misfit and does not require any forward modeling. We then perform a misfit screening based on the similarity between observed waveforms and the synthetics predicted by the solution of a first $\mathrm{W}$ phase inversion. Those channels showing a very bad fit between data and synthetics are removed from the dataset. Finally, a noise screening is made as follows. The displacement power spectral densities (PSD) are first computed for all remaining stations using 3 hours of signal preceding the 2011 Tohoku Earthquake. We then reject any channel for which the average difference between its noise spectrum and the New Low Noise Model (NLNM) in the frequency band $1-5 \mathrm{mHz}$ is above $30 \mathrm{~dB}$. From the 217 channels available within $\Delta \leq 90^{\circ}, 96$ channels (69 stations) survived the complete screening process. Most of them correspond to vertical component seismograms (LHZ channels), the horizontal components usually being noisier (e.g. Lambotte et al., 2006). Using this low-noise dataset, we perform a $\mathrm{W}$ phase inversion including a spatial and temporal grid search for the centroid latitude, longitude, depth, and timing. Table 2 and Fig. 2 show the updated $\mathrm{W}$ phase CMT (WCMT) inversion results.

As shown in Fig. 3, the synthetics computed from the WCMT solution match remarkably well the observed traces within the $\mathrm{W}$ phase time window. The optimum centroid depth of $19.5 \mathrm{~km}$ as well as the dip of about $12^{\circ}$ agree quite well with the SLAB1.0 geometry in this region (Hayes et 
Table 2. Optimal post-mortem W phase Centroid Moment Tensor obtained for the 2011 Tohoku Earthquake using low-noise data.

\begin{tabular}{|c|c|c|c|c|c|}
\hline $\begin{array}{r}\mathrm{Cer} \\
37.92^{\circ} \mathrm{N}, 14\end{array}$ & $\begin{array}{l}\text { location: } \\
\text { E, depth } 19.5 \mathrm{~km}\end{array}$ & \multicolumn{4}{|c|}{$\begin{array}{c}\text { Centroid timing: } \\
\text { 2011/3/11 5:46:23.00 UTC + } 68 \text { sec (h.d.: } 68 \mathrm{sec})\end{array}$} \\
\hline \multicolumn{6}{|c|}{ Moment tensor $\left(M_{\mathrm{w}}=9.02\right)$} \\
\hline \multicolumn{2}{|c|}{$r r / \theta \theta / \phi \phi / r \theta / r \phi / \theta \phi(\times 1.0 \mathrm{e} 22$ N.m $)$} & \multicolumn{4}{|c|}{ Principal axis } \\
\hline \multicolumn{2}{|c|}{$1.695 /-0.147 /-1.548 / 1.403 / 3.637 /-0.534$} & eigenvalue & 4.252 & 0.031 & -4.273 \\
\hline \multicolumn{2}{|c|}{ Best double couple $\left(M_{\mathrm{o}}=4.26 \mathrm{e} 22 \mathrm{~N} \mathrm{~m}\right)$} & plunge & $57^{\circ}$ & $1^{\circ}$ & $33^{\circ}$ \\
\hline $196^{\circ} / 12^{\circ} / 85^{\circ}$ & $21^{\circ} / 78^{\circ} / 91^{\circ}$ & azimuth & $292^{\circ}$ & $201^{\circ}$ & $110^{\circ}$ \\
\hline \multicolumn{6}{|c|}{ Solution quality } \\
\hline chans/stats: $96 / 69$ & misfit rms: $0.195 \mathrm{~mm}$ & \multicolumn{2}{|c|}{ norm. rms: 0.164} & \multicolumn{2}{|c|}{ azim. gap: $31.6^{\circ}$} \\
\hline
\end{tabular}

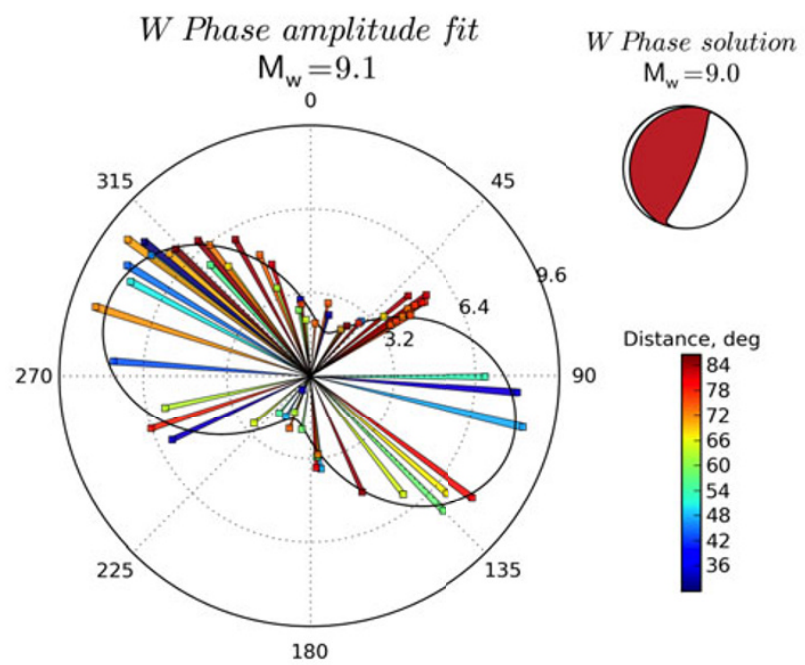

Fig. 1. W phase preliminary amplitude fit for the 2011 Tohoku Earthquake. A polar representation is used: the angle and radius correspond respectively to the station azimuth and amplitude value. The continuous line represents the result of the regression determined from $\mathrm{W}$ phase amplitudes. The updated $\mathrm{W}$ phase centroid moment tensor solution shown in Fig. 2 is displayed for comparison.

al., 2009; USGS, 2011c). The difference between the W phase magnitude $M_{\mathrm{w}}=9.0$ and the Global CMT (gCMT, 2011) $M_{\mathrm{w}}=9.1$ may be due to the well-known trade-off between dip and scalar moment for shallow sources as seen with long period data (Kanamori and Given, 1981). In fact, running the $\mathrm{W}$ phase inversion, with a fixed dip of $10^{\circ}$ (the dip of the shallow plane of the gCMT best double-couple), gives $M_{\mathrm{w}}=9.1$. However, since the fault ruptured over several hundred kilometers down-dip over a portion of the slab with significant variation in dip, a strict interpretation of the dip of a point source is not meaningful.

\section{Scalar Seismic Moment at Very Long Period}

As mentioned above, the standard $\mathrm{W}$ phase source inversion algorithm exploits the frequency content between 1 and $5 \mathrm{mHz}$. Lower frequencies usually lead to instability due to the presence of the well-known global long period background noise, especially noticeable on horizontal traces. However, for very large events like the 2011 Tohoku $\left(M_{\mathrm{w}}=9.0\right)$, or the 2004 Sumatra-Andaman $\left(M_{\mathrm{w}}=9.2\right)$ earthquakes, it should be possible to use even lower frequencies, making it possible to explore the very long period characteristics of the source, and in particular to test

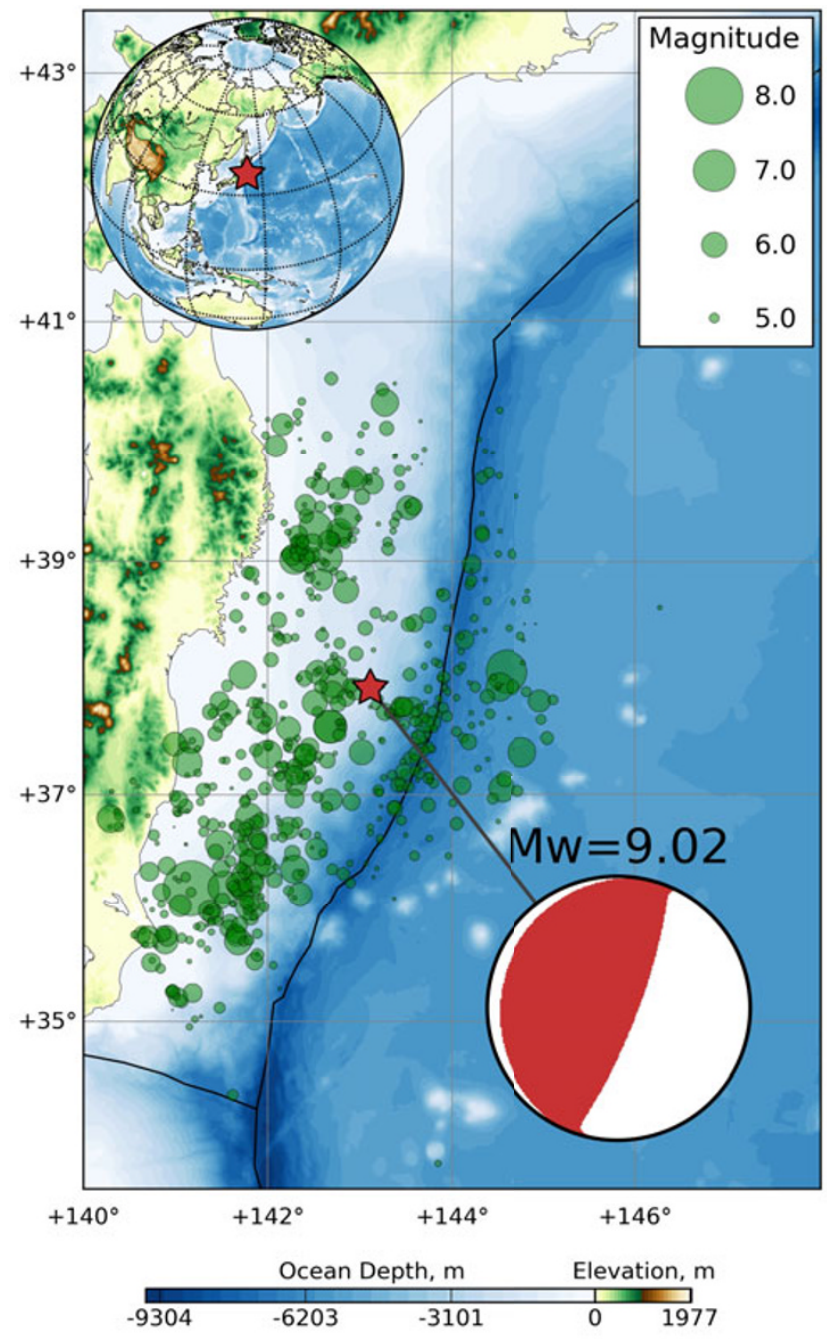

Fig. 2. Updated $\mathrm{W}$ phase centroid moment tensor solution obtained for the 2011 Tohoku Earthquake. The green circles correspond to USGS locations of events occurring between 2011-03-11 and 2011-03-20.

for possible long period, additional slow slip which could be overlooked when using the standard frequency band. We proceed as follows: recognizing that the vertical components are less prone to long period noise perturbation, we further restrict the data set to include only vertical data, and fix the dip to the value obtained above $\left(11.9^{\circ}\right)$. We then make a first constrained inversion (inverting for a double couple with a fixed dip) using the original frequency band $(1-5 \mathrm{mHz})$. This moment is then used as a reference for 

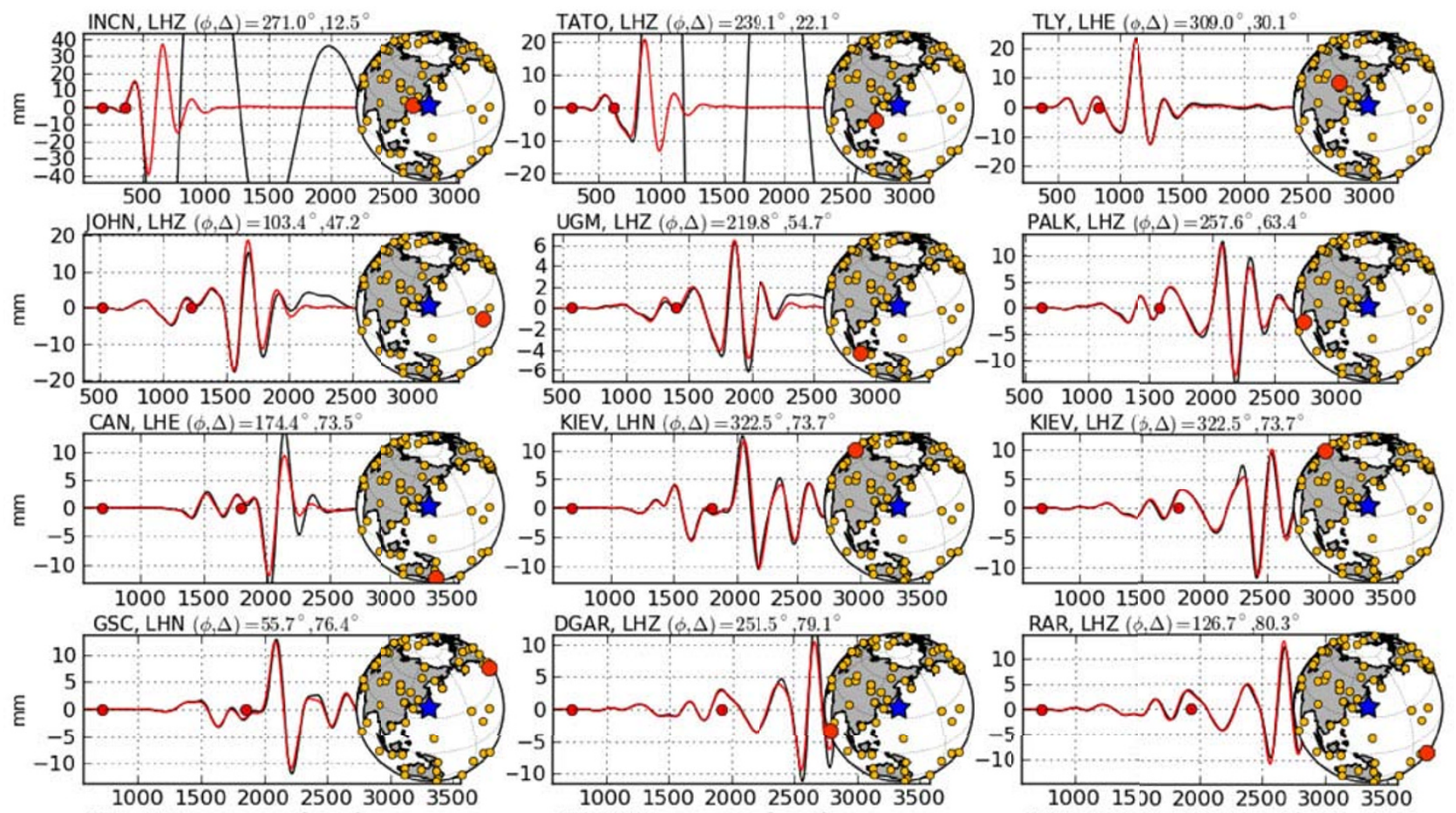

RAR, $\operatorname{LHZ}(\phi, \Delta)=126.7^{\circ}, 80.3^{\circ}$
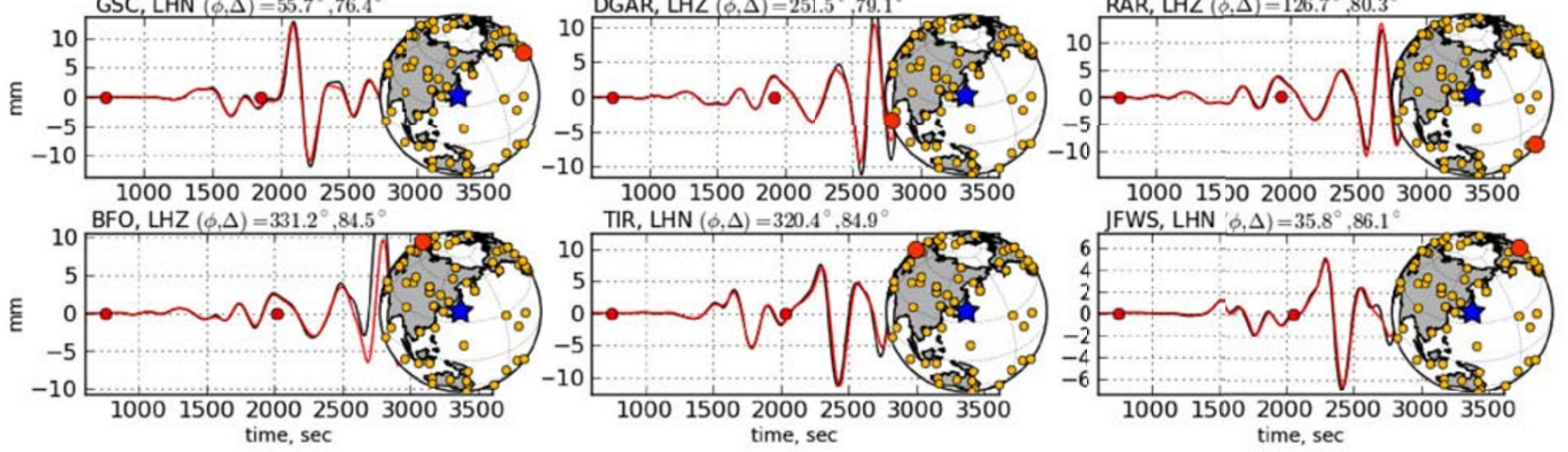

Fig. 3. Examples of observed waveforms (black lines) and the corresponding synthetics (red lines) computed from the updated W phase solution. The station azimuth $(\phi)$ and epicentral distance $(\Delta)$ are indicated, as well as the W phase time window, bounded by red dots. W phase and later arrivals are often very well predicted by the updated solution. For some channels like INCN-LHZ or TATO- LHZ, the surface waves are affected by instrument problems, though the $\mathrm{W}$ phase signal is not affected.

Table 3. Summary of results for the application of the W phase source inversion algorithm with longer period frequency bands. Run " 0 " yields $\operatorname{dip}=11.9^{\circ}$. This value is used to fix the dip in subsequent runs, to avoid the moment-dip trade-off effect.

\begin{tabular}{ccccc}
\hline & Bp-filter $(\mathrm{mHz})$ & \# channels & $M_{\mathrm{w}}$ & Constraints \\
\hline 0 & $1.00-5.00$ & $96(\mathrm{ZNE})$ & 9.02 & Zero-trace (standard algorithm) \\
1 & $1.00-5.00$ & $63(\mathrm{Z})$ & 9.02 & Double couple, Fixed dip \\
2 & $0.75-4.00$ & $64(\mathrm{Z})$ & 9.01 & Double couple, Fixed dip \\
3 & $0.60-3.00$ & $59(\mathrm{Z})$ & 9.02 & Double couple, Fixed dip \\
4 & $0.50-2.00$ & $64(\mathrm{Z})$ & 9.03 & Double couple, Fixed dip \\
\hline
\end{tabular}

three additional similar inversions (constrained inversions using only vertical data), each performed using three different frequency bands: $0.75-4 \mathrm{mHz}, 0.6-3 \mathrm{mHz}$, and $0.5-$ $2 \mathrm{mHz}$. Table 3 summarizes the results.

No significant variation of $M_{\mathrm{w}}$ with frequency can be seen in this experiment. The small observed variation of $M_{\mathrm{w}}$ is one order of magnitude smaller than the variation caused by dip or depth uncertainties.

\section{Discussion and Conclusion}

We reported here on the performance of the $\mathrm{W}$ phase source inversion algorithm for the 2011 Tohoku Earthquake. The algorithm was independently running at three organizations at the time of the 2011 Tohoku Earthquake (USGS, PTWC and IPGS). Results good enough for tsunami warning purposes were obtained at the USGS and the PTWC within $20 \mathrm{~min}$ of the event origin time. Over the next hour, the $\mathrm{W}$ phase solutions improved, and converged to a common result, as more data became available. Also, the centroid location, around $38.5^{\circ}$ and $143.0^{\circ}$, indicated that the source was offshore, fairly close to the Japan Trench. Knowing the large magnitude, $M_{\mathrm{w}} \approx 9$, and the offshore location soon after the origin time can be a key element for suggesting the occurrence of an extraordinary event and the necessity for initiating large-scale rapid emergency activities.

Since it took 20 min to obtain the first solution using the global data, a faster method is desirable for regional tsunami warning purposes.

Earlier, we demonstrated (Kanamori and Rivera, 2008b; 
Rivera and Kanamori, 2009) that if regional data such as the Japanese F-net data are available in real-time, it is possible to shorten the $20 \mathrm{~min}$ solution-time to as little as $6 \mathrm{~min}$. Thus, with the advent of high-quality seismic data and highrate GPS data at regional distances, we believe that the $\mathrm{W}$ phase inversion method can yield key information for effective, rapid regional tsunami warning. For this event we tested the inversion using the F-net data after they became available on April 26, 2011. Using the data from $5^{\circ}$ to $12^{\circ}$, we obtained a solution with $M_{\mathrm{w}}=9.1$ and a best double couple given by $\left(\right.$ strike $/ \mathrm{dip} / \mathrm{rake}=201^{\circ} / 10^{\circ} / 92^{\circ}$ ). Because of the limited azimuthal coverage, the centroid location cannot be constrained well. Nevertheless, the solution is adequate for early warning purposes. In this case, the entire analysis would have been completed about $7 \mathrm{~min}$ after O.T.

For the 2011 Tohoku Earthquake, the first tsunami arrived at the coastal areas in about $15 \mathrm{~min}$. It is difficult to determine the exact tsunami arrival times at Miyako, Kamaishi, Ofunato, and Ayukawa (the most severely affected cities) because of clipping of tide gauge records. However, a GPS wave gauge GPS1 operated by Port and Airport Research Institute (PARI) is located just offshore of Kamaishi. On this record (PARI, 2011), after the disturbance due to the arrival of seismic waves and ground subsidence, the water level started rising gradually at 15:01 JST (approximately $15 \mathrm{~min}$ after O.T.), then rapidly at 15:07:30 JST (approximately $21 \mathrm{~min}$ after O.T.), and reached a maximum at 15:12 JST (approximately $26 \mathrm{~min}$ after O.T.).

To improve the real-time results, post-mortem $\mathrm{W}$ phase inversions have been conducted. The strategy was to improve the signal-to-noise ratio by including a pre-inversion screening scheme using additional criterion based on measured long period pre-event noise. The solution obtained is an almost pure double couple (non-double couple $=0.7 \%$ ), with a scalar moment of $4.26 \mathrm{e}+29$ dyn-cm $\left(M_{\mathrm{w}}=9.02\right)$ and a shallow dipping fault plane of $11.9^{\circ}$. For the purpose of testing for a possible seismic moment variation at very long periods, we performed additional $\mathrm{W}$ phase inversions using increasingly long period band pass filters. We found no evidence of such variation, thus confirming the scalar moment value discussed above.
Acknowledgments. We thank Dr. A. Hutko and an anonymous reviewer for their helpful comments on the manuscript. This work uses Federation of Digital Seismic Networks (FDSN) seismic data. The Incorporated Research Institutions for Seismology (IRIS) Data Management System (DMS) and the F-Net (NIED) data centres were used to access the data.

\section{References}

Duputel, Z., L. Rivera, H. Kanamori, and G. P. Hayes, W-phase fast source inversion for moderate to large earhquakes $\left(M_{\mathrm{w}} \geq 6.5,1990-2010\right)$, Geophys. J. Int., 2011 (in revision).

EMSC, Rapid Determination of Source Parameters operated at LDG (Paris) and IGN (Madrid), issued at 06:09 UTC 11 mar 2011, 2011.

gCMT, http: / / www.globalcmt . org, 2011.

Hayes, G. P., D. J. Wald, and K. Keranen, Advancing techniques to constrain the geometry of the seismic rupture plane on subduction interfaces a priori-higher order functional fits, Geochem. Geophys. Geosyst., 10, 2009.

Hayes, G. P., P. Earle, H. Benz, D. Wald, R. Briggs, and the USGS/NEIC Earthquake Response Team, 88 hours: The US Geological Survey National Earthquake Information Center response to the March 11, 2011 $M_{\mathrm{w}} 9.0$ Tohoku earthquake, Seismol. Res. Lett., 2011 (in press).

Kanamori, H. and J. W. Given, Use of long-period surface waves for rapid determination of earthquake source parameters, Phys. Earth Planet. Inter., 27, 8-31, 1981.

Kanamori, H. and L. Rivera, Source inversion of W phase: speeding up tsunami warning, Geophys. J. Int., 175, 222-238, 2008a.

Kanamori, H. and L. Rivera, Application of the W phase source inversion method to regional tsunami warning, Collection of Conference papers, International Conference on Tsunami Warning, Towards Safer Coastal Communities, Bali, Indonesia, November 12-14, 2008b.

Lambotte, S., L. Rivera, and J. Hinderer, Vertical and horizontal observations of tides, J. Geodyn., 41, 39-58, 2006.

PARI, http://www.pari.go.jp/info/tohoku-eq/ $20110328 \mathrm{mlit}$. html, 2011.

PTWC, Tsunami bulletin number 001, issued at 05:55 UTC March 11 2011, 2011.

Rivera, L. and H. Kanamori, Using W phase for regional tsunami warning and rapid earthquake hazard assessment. The 2nd International Workshop on Earthquake Early Warning, Kyoto, Japan, April, 2009.

USGS, http://earthquake.usgs.gov/earthquakes / shakemap, 2011a.

USGS, http://earthquake.usgs.gov/earthquakes / eqinthenews / 2011 / usc0001xgp/finite_fault_ 1 .php, 2011 b.

USGS, http://earthquake.usgs.gov/research/data/ slab, 2011c.

Z. Duputel (e-mail: zacharie.duputel@unistra.fr), L. Rivera, H. Kanamori, G. P. Hayes, B. Hirshorn, and S. Weinstein 